\title{
On Definite Plural NP's and the Meaning of all
}

\author{
Christine Brisson \\ Rutgers University
}

\section{The Problem}

When we compare (1) and (2) we find that (2) is a stronger statement than (1), in that (2) somehow more strongly requires that each boy be hungry.

(1) The boys are hungry

(2) The boys are all hungry

A first pass at how to capture this difference might be to treat all as introducing universal quantification over the set denoted by the boys. However, the examples in (3-6) show that more must be said because all can felicitously combine with the collective predicate gather, and it does not disambiguate the mixed predicate build a raft in favor of a distributive reading. In these respects all contrasts with the universal quantifiers every and each.

(3) The students gathered in the hallway

(4) The students all gathered in the hallway

(cf. ??Every/each student gathered in the hallway)

(5) The girls built a raft (distributive or collective)

(6) The girls all built a raft (distributive or collective)

(cf. Every/each girl built a raft (distributive only))

What (2), (4), and (6) have in common, despite the different types of predicates, is that all seems to make a sentence stronger.' Link (1983) called this "the totality effect" and Dowty (1987) called it "the maximizing effect."

The difficulty of saying what all means lies in capturing the totality effect of all, while allowing for it to combine with collective predicates like gather and build a raft. Link's approach to this problem was to introduce a semantic primitive ${ }^{\mathrm{T}}$, which is read "partakes in." The ${ }^{\mathrm{T}}$ operator distributes down to each atomic individual in the subject NP the property of "partaking in" the action described by the predicate. So, for example, in the case of (4), the presence of all ensures that each individual student took part in the gathering. Where we have a distributive predicate like be hungry, "partaking in" being hungry is equivalent to being hungry.

Dowty takes Link's approach as a starting point and proposes that all operates on a lexical property of predicates that he calls "distributive subentailments."

(C) 1997 by Christine Brisson

Aaron Lawson (ed), SALT VII, 55-72, Ithaca, NY: Cornell University. 
Distributive subentailments describe what is required of each individual in the collective action in order for the action to come about. For example, the distributive subentailments of gather are something like, 'come to be in a common location at the same time as a lot of other people.' In the case of distributive predicates, distributive subentailments equal simple distributivity.

One possible objection to these proposals is that they introduce new semantic (or lexical) primitives for which there is no evidence, independent of all. And Taub (1989) has criticized Dowty's proposal on the grounds that his argument for the existence of subentailments is circular. But the argument I want to make against these proposals is based on a different problem, to which I now turn.

It is clear that the effect of all is to somehow strengthen the truth-conditions of a sentence with a definite plural NP subject. But the problem is, the meaning we assign to these sentences is already quite strong without all.

Consider for now only the case of sentences with predicates that are distributive, like be hungry. Let us assume that a definite plural NP like the boys denotes a (first-order) set. On most theories of definite plurals, to interpret (7) we introduce a covert distributivity operator on the plural predicate (as in (8), using Link's ${ }^{\mathrm{D}}$ ), which has the effect of introducing universal quantification over the members of the set that the subject denotes, as shown in (9).

(7) The boys are hungry

(8) 'Dhungry'(the.boys)

(9) $\forall \mathrm{x}[\mathrm{x} \in$ lthe.boysl $\rightarrow \mathrm{x} \in$ lhungryl $]$

(10) The boys are all hungry

This interpretation is common to theories of plurality such as Link (1983), Lasersohn (1990, 1995), and Schwarzschild (1992, 1996) (Exceptions include Landman 1989 and Schein 1993).

But now we have a problem: it is clear, as we have already said, that (10) more strongly requires that each boy be hungry than (7). However, the interpretation we have assigned to (7) is already quite strong. How could (10) be stronger than the universally-quantified expression in (9)?

To be sure, this problem has been noticed before. The discussion in Dowty (1987) makes it clear that he was aware of this problem, but he did not give any explicit semantic account of it. And Lasersohn (1993, ftn. 3) also notices it.

I take it that we cannot give a coherent semantics for all until we have a weaker semantics for sentences with definite plural NP's. In what follows I will argue that we have independent reasons for weakening these sentences, and then propose a theory that allows for weakening. I then propose a semantics for all in which we do not need new semantic primitives to capture its strengthening effect.

\section{Pragmatic Weakening}

It has been widely noticed that sentences with definite plurals in subject position 
allow exceptions with more freedom than, say, sentences with universal quantifiers in subject position. It is also noted that the phenomenon seems to have a pragmatic character. For example, if the boys happens to denote a very big set of boys (say, the boys at a large single-sex prep school) then it is quite easy to allow 'loose' truth conditions for a sentence about the boys. Since the size of the set denoted by the boys is contextually determined, it is clear that this is at least in part a pragmatic effect. So I call this effect "pragmatic weakening."

Other authors have noted this effect in very specialized sorts of contexts. For example, we seem to allow for looser truth conditions when we understand a group of individuals to be operating as a team in some sense, as has been discussed extensively by Lasersohn (1995) and Landman (1996).

I want to argue here that pragmatic weakening is not a peripheral or specialized phenomenon that our semantics can afford to ignore but rather a core property of definite plurals. It occurs much more frequently than has been acknowledged, and does so with a wide range of predicates on the spectrum from strongly distributive to mixed-extension to collective. ${ }^{2}$

For example, suppose Stan and Tom are counselors in a boy's summer camp. Stan can remark that they had better serve dinner soon, because

The boys are hungry

Stan's statement counts as true, even if one or two of the boys is not hungry. (Dowty 1987 also makes essentially the same point.) And it counts as true even if the group is relatively small, with just six or seven members. ${ }^{3}$ We're not concerned with each and every boy, partly because the context of utterance just doesn't demand that much precision. And of course be hungry is a distributive predicate.

We see the same effect with collective predicates. Suppose Kerry and Jane are counselors across the lake at the girls' camp, and the girls of Cabin \#10 were assigned the job of building a raft together. If they do it, then Kerry can say

(12) The girls built a raft

Again, (12) is true even if Alice was back in the cabin taking a nap while the others worked. And this sort of 'exception-allowing' has the exact same feel as what we saw in (11), suggesting that pragmatic weakening with both distributive and collective predicates has a common source. Whatever we ultimately say about pragmatic weakening, it will need to apply both to distributive and to collective predicates.

There is other, independent evidence that pragmatic weakening should be part of the semantics of definite plurals. When we apply some standard tests for entailment versus implicature, the purported universal force of plural definites comes out to look more like an implicature than an entailment. For example, the universal force of plural definites is cancelable without contradiction. (Grice; see also Levinson 1983, Horn 1989) Compare (13) and (14) with the infelicitous (15).

The boys are hungry, but Adam isn't/but not all of them. 
(14) The girls built a raft, but Mary slept through it/but not all of them.

(15) \#John managed to solve the problem but he didn't solve it.

The alleged universal force is also reinforceable without redundancy (Sadock 1978).

(16) The boys -- in fact, all the boys -- are hungry

(17) The girls -- in fact, all the girls -- built a raft

(18) \#John managed to -- and in fact did -- solve the problem

I conclude that we need a semantics for definite plurals that gives them somewhatless-than-universal force, and takes into account the pragmatic nature of the weakening.

\section{Making Room for Pragmatic Weakening in the Semantics}

Here I propose a semantics for definite plurals that builds primarily on the theory of Schwarzschild (1994, 1996), which I will call the "generalized distributivity" theory.

The generalized distributivity theory of plurals has two components that will be crucial for me here. First, the theory incorporates the idea of covert distributivity (ie, Link's ${ }^{\mathrm{D}}$ operator), but generalizes it so that distributivity isn't always 'all the way down' to atomic individuals: Schwarzschild gives convincing arguments that sometimes we want our distributivity operator to distribute only down to subsums of a plurality.

Secondly, information about exactly what subparts of a plurality the D operator is supposed to distribute down to comes from the pragmatic context of utterance. So if we are in a context where sums of individuals are salient, then the context provides this information to the $\mathrm{D}$ operator; if we are in a context where atomic individuals are salient, then the context can provide this information to the $\mathrm{D}$ operator. This is accomplished by means of a variable whose value is contextually assigned. The $\mathrm{D}$ operator introduces universal quantification and the variable restricts the quantification to just the contextually salient sums or atomic individuals.

Schwarzschild calls his D operator Part, for partition, and the contextdependent variable is called $\operatorname{Cov}$, because the value assigned to the variable always takes the form of a cover of the universe of discourse. From now on I will use these terms.

Let us see how Part and Cov work together in the interpretation of a sentence by means of the following, by-now-familiar example.

(19) The boys are hungry

In translation, our covert distributivity operator Part applies to the plural predicate, yielding (20). 
(20)

$($ Part $($ Cov $)($ hungry') $)($ the.boys')

(20) is interpreted according to the rule in (21), yielding the interpretation in (22).

Interpretation rule (based on Schwarzschild 1996):

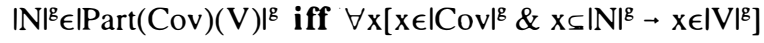

$\forall \mathrm{x}\left[\mathrm{x} \in\left|\operatorname{Cov}^{\mathrm{g}} \& \mathrm{x} \subseteq\right|\right.$ the.boys $\mathrm{s}^{\mathrm{g}} \rightarrow \mathrm{x} \in \mid$ hungry $\left.\left.\right|^{\prime}{ }^{\mathrm{g}}\right]$

Note that the universal quantifier contributed to (22) by the Part operator has two conditions in its restriction: it takes the set denoted by the boys (as in the standard use of a distributivity operator) and it takes a contextually-determined cover of the universe of discourse.

So in order to evaluate the truth conditions of (22), we must invent a universe of discourse and assign a value to Cov. A universe $\mathrm{U}$ and some possible covers of the set of singularities of $U$ is given in (23).

$\mathrm{U}=\{\mathrm{a}, \mathrm{b}, \mathrm{c}, \mathrm{s}, \mathrm{t},\{\mathrm{a}, \mathrm{b}\},\{\mathrm{a}, \mathrm{c}\},\{\mathrm{a}, \mathrm{s}\},\{\mathrm{a}, \mathrm{t}\},\{\mathrm{a}, \mathrm{s}, \mathrm{t},\} \ldots\}$

Ithe.boys $\left.\right|^{\mathrm{g}}=\{\mathrm{a}, \mathrm{b}, \mathrm{c}\}$

$I=\{\{a\},\{b\},\{c\},\{s, t\}\}$

$J=\{\{a\},\{c\},\{b, s\},\{t\}\}$

$\mathrm{K}=\{\{\mathrm{a}, \mathrm{b}, \mathrm{c}\},\{\mathrm{s}\},\{\mathrm{t}\}\}$

$\mathrm{L}=\{\{\mathrm{a}, \mathrm{b}\},\{\mathrm{c}, \mathrm{s}\},\{\mathrm{t}\}\}$

Suppose the context assigns the value I to Cov. Then the sentence will be interpreted exactly as we saw earlier in (7), because since each boy occupies a singleton set of the cover assigned to Cov, each boy is asserted to be in the extension of be hungry. In other words, assignment of a cover like I leads to a distributive interpretation of the sentence.

Now consider the mixed predicate build a raft. The sentence is translated as in (25), and interpreted as in (26).

(24) The boys built a raft

(25) $\quad($ Part (Cov)(built.raft'))(the.boys')

(26) $\forall x\left[x \in|C o v|^{8} \& x \subseteq \mid\right.$ the.boys $\left.\right|^{8} \rightarrow x \in \mid$ lbuilt.raft $\left.\left.\right|^{8}\right]$

If the context assigns I to Cov in (25), the sentence will be interpreted distributively, and for exactly the same reason as (20), above, was. In other words, the sentence will assert three separate raft-buildings.

On the other hand, if the context assigns $\mathrm{K}$ to Cov, then the sentence will assert that the set containing the boys is in the extension of build a raft; in other words, it will assert that there was a single collective raft-building.

So the responsibility for whether a sentence is interpreted distributively or collectively lies in part with the context. If the context makes clear that we are 
talking about individual boys, then Cov will take I as its value. If the context makes clear that we are talking about some collective action by the boys, then Cov will take $\mathrm{K}$ as its value. (If the context is not clear on this point, then there are other devices the language makes available to clarify: words like together and each. See Schwarzschild 1994 for discussion.)

I say "in part" because we must also assume that the lexical semantics of the predicate plays some role in constraining the felicity of certain types of covers. For example, if we assume be hungry is a predicate that applies only to atomic individuals, then we must assign a Cov that has singleton cells, or else the sentence would be doomed to be false. Likewise, the fact that we may choose a cover with singleton or non-singleton cells for a mixed predicate like build a raft is information that comes from the predicate itself.

To sum up, the distinction between distributive and collective readings of a sentence is captured not by means of distinct NP types such as groups and sums (as in Landman 1989, Lasersohn 1995), but by means of a generalized distributivity operator whose interpretation is partly context dependent.

\subsection{More on the Assignment of Values to $\mathrm{Cov}$}

Lasersohn (1995) raises the following objection to the generalized distributivity theory. Since the value of $\mathrm{Cov}$ is a cover of the whole universe of discourse, it is possible that the value $\mathrm{J}$ be assigned to Cov in (20), repeated below as (27).

(27) (Part(Cov)(hungry'))(the.boys')

(28) $\forall x\left[x \in|C o v|^{8} \& \mathrm{x} \subseteq \mid\right.$ the.boys $\left.\right|^{\prime \mid} \rightarrow x \in \mid$ hungry $\left.\left.\right|^{8}\right]$

(29) $\quad J=\{\{a\},\{c\},\{b, s, t\}\}$

The difference between $\mathbf{J}$ and $\mathrm{I}$ is that in $\mathrm{J}$ Bill does not occupy a singleton cell: he is in a cell with the two non-boys, Stan and Tom. Call this an ill-fitting cover, because it is ill-fitting with respect to the set of boys -- there is no set of covers whose union is equivalent to the set of boys.

A consequence of assigning this type of cover to Cov in (27) is that the semantics in some sense 'doesn't care' whether Bill is hungry or not. Since the set $\{b, s, t\}$ is not a subset of the set $\{a, b, c\}$, there is no cell containing Bill that satisfies the restriction of the quantifier. The sentence can come out true whether Bill is hungry or not.

Lasersohn objects that this is highly undesirable, on the grounds that it means that John and Mary went to school could come out true even if Mary stayed home, a somewhat counterintuitive result. In response, Schwarzschild argues that to allow such a choice of cover would be so uncooperative of a speaker as to be"pathological," and suggests that while it might be possible to formulate a rule that prevents the choice of such a cover, it is more plausible to simply assume that pathological covers are ruled out on general principle.

I agree with Schwarzschild that we should assume that speakers are cooperative in their intended choice of covers, but wish to suggest that ill-fitting 
covers are not necessarily so 'pathological' as either he or Lasersohn believe them to be. We quite commonly find ourselves in circumstances where it is not necessary to be precise down to each and every individual, as our summer camp scenarios from section 2 were intended to show. So perhaps in precisely these circumstances illfitting covers do some work for us -- they allow us to be a little bit vague.

I propose that we should allow for the possibility of ill-fitting covers. This gives us a way to capture pragmatic weakening without any further revision to our semantics on the generalized distributivity theory of plurals. Furthermore, since it is the job of pragmatics to assign a value to $\mathrm{Cov}$ in the first place, by capturing pragmatic weakening with ill-fitting covers, we have put responsibility for pragmatic weakening in its proper place: in the pragmatics.

We can rely on the cooperativeness of speakers to ensure that pragmatic weakening does not go too far. For example, compare the sentences in (30) and (31).

The boys are hungry

(31) The boys passed the final exam

It is easy to imagine a situation in which (30) is true, even though not every boy is hungry (see section 2). On the other hand, it would be pretty uncooperative to report (31) to the school principal when in fact three boys failed, because the principal must be concerned with the failing or passing of each student.

Finally, it should be pointed out that pragmatic weakening works the same way for collective predicates as it does for distributive predicates. The proposal I make here inherits from the generalized distributivity theory the feature that collective and distributive predication are not separate mechanisms of the grammar. So we don't need to make any independent statement about how pragmatic weakening might work with 'groups' or other entities.

For example, take (32) on a collective reading, meaning that the boys together built a single raft.

$$
\begin{aligned}
& \text { The boys built a raft } \\
& (\text { Part }(\operatorname{Cov})(\text { built'))(the.boys') } \\
& \forall x\left[x \in|\operatorname{Cov}|^{\mathrm{g}} \& \mathrm{x} \subseteq \mid \text { the.boys' }\left.\right|^{\mathrm{g}} \rightarrow \mathrm{x} \in \mid \text { built.raft }\left.\right|^{\mathrm{g}}\right] \\
& \mathrm{L}=\{\{\mathrm{a}, \mathrm{b}\},\{\mathrm{c}, \mathrm{s}, \mathrm{t}\}\}
\end{aligned}
$$

Suppose Adam and Bill did all the work, while Chris drank lemonade. Then we might be willing to assert (32) as true. If we are, we can assign a cover like L to Cov in (33). Since L is an ill-fitting cover that puts Chris in a cell with non-boys, the sentence makes no assertion about whether Chris actually participated in the raftbuilding.

I should point out that although I use very specific values for Cov in my illustrations, I do not suppose that speakers and hearers are always aware of the values to such a high level of precision. It is more accurate to say that speakers and hearers are in some sense guessing at the sort of cover that the other has in mind. I take it that this is true for pragmatically-determined domain-of-quantification 
variables in general (see von Fintel 1994 for some discussion). What is important is that we allow for the possibility of ill-fitting covers. Then the process of figuring out what value one's conversational partner has in mind will mean that one has to leave open the possibility of an ill-fitting cover, and thus of pragmatic weakening.

\section{One Consequence: A Proposal for the Semantics of all}

In this section I will propose that the 'maximizing' or 'totality' effect of all is essentially an 'anti-pragmatic-weakening' effect. We will see that one consequence of this approach is that all does not have any quantificational force of its own.

Recall that the contrast to be explained is the one in (36-37).

(36) The boys are hungry

(37) The boys are all hungry

The difference between these two sentences is that (37) is a stronger statement than (36). Given the proposal I made in section (3), we can say that the source of the weakness of (36) is the fact that it allows at least for the possibility of pragmatic weakening.

In contrast, let us say that all's contribution to (37) is to rule out the possibility of pragmatic weakening. It does this by disallowing the choice of an ill-fitting cover. Or, another way to say this is that all requires a good-fitting cover, where good fit is to be understood as the opposite of ill fit.

Let us define a relation good fit between a cover and an NP-denotation (i.e. a set). A cover is a good fit for this set if there isn't any element or member of the set that's stuck in a cell with some non-members. Another way to say this is that the cover is a good fit if every element of the set is in a cell of the cover that is a subset of that set. We can define this formally as in (38).

Good fit: $\left.\operatorname{lgf}(\operatorname{Cov})(X)\right|^{8}$ is true iff $\forall y\left[y \in X \rightarrow \exists Z\left[Z \in \mid \operatorname{Cov}^{8} \& y \in Z \& Z \subseteq X\right]\right]$

The contribution of all to a sentence is simply to demand that the value assigned to Cov is a good fit. So (37) can be translated according to the translation rule in (39).

(39) Translation rule for sentences with all:

A sentence of the form [ ${ }_{5} \mathrm{NP}$ all VP] where $\mathbf{N}$ is the translation of $\mathrm{NP}$ and $\operatorname{Part}(\mathrm{Cov})(\mathbf{V})$ is the translation of VP, has the following translation: $(\operatorname{Part}(\mathrm{Cov})(\mathbf{V}))(\mathbf{N}) \& \operatorname{gf}(\mathrm{Cov})(\mathbf{N})$

(40) The boys are all hungry

(41) (Part(Cov)(hungry'))(the.boys') \& gf(Cov)(the.boys')

This translation rule and the definition of good fit in (38) guarantee that (37) can only be true if each boy is hungry. This accounts for the judgment that (37) is 'stronger' 
than (36). (36) may be judged true in some contexts where not every boy is hungry; (37) will never be judged true in such a context.

Because I have adopted from the generalized distributivity theory a mechanism for collectives that is the same as for distributives, except for the value assigned to the variable Cov, this hypothesis about the meaning of all can be applied to collective predicates straightforwardly. There is no need to introduce new semantic primitives such as ${ }^{\mathrm{T}}$ or distributive subentailments.

The good fit relation applies in exactly the same way to collectives. So (42) is translated as (43).

(42) The boys all built a raft

(43) (Part(Cov)(built'))(the.boys') \& gf(Cov)(the.boys')

Because all imposes a good fit requirement on the value assigned to Cov, (42) cannot be true in a context where one of the boys did not participate in the raft building.

\subsection{Collective Predicates}

I say in the previous section that the account of all given here predicts that we should expect all to occur with collective predicates. This is true, and it means that I do not face the problem that Dowty and Link faced, which was how all can combine with collective predicates.

But instead, I face an inverse problem, because although it is true that all occurs with some collective predicates, there are other collectives that do not allow all. Instead of trying to explain why all can occur with any collective predicates, I have to explain why there should be any collective predicates that disallow all.

There is a subclass of collective predicates that don't allow all that Dowty called "pure cardinality predicates." He had in mind predicates like be a big group, and be numerous.

\#The boys are all a big group

Taub (1989) expanded on Dowty's class with the following examples of predicates that also disallow all.

(45) \#The senators all passed the pay raise

(46) \#The students all elected a president

Taub gave an interesting account of this subclass of collective predicates: she pointed out that they pattern as states and achievements in their aktionsart classification. The collective predicates that do allow all, in contrast, are activities and accomplishments. Unfortunately Taub does not offer an explanation for this fact, and I do not have anything to say about it here either.

What I do wish to point out about these predicates is that they also do not allow pragmatic weakening. We can see this by applying the same tests for 
entailment/implicature that we saw earlier in section (2). For example, we saw earlier that in a sentence like the boys are hungry, the 'maximality' of the boys can be denied without contradiction. This is not so for the sentences in (47-48), which are quite odd.

(47) \#The boys are a big group, but not John and Bill /but not all of them

(48) ??The students elected a president, but Kerry and Jan didn't do anything/but not all of them.

We also saw that the 'maximality' of the plural NP could be reinforced without redundancy, but again, with the subclass of predicates that disallow all, the sentences come out distinctly odd.

(49) ??The boys -- in fact, the entire lot of them -- are a big group

(50) ??The students -- in fact, the entire lot of them -- elected a president

I conclude that these sentences do not allow pragmatic weakening.

If the function of all is to eliminate the possibility of pragmatic weakening, then it is clear on an intuitive level why all should be infelicitous with these predicates: it cannot possibly add anything to the sentence. Let us implement this formally by supposing that felicitous use of all presupposes that pragmatic weakening is possible. With predicates that do not allow pragmatic weakening, this presupposition is not satisfied and so the infelicity of (44)-(46) is a case of presupposition failure.

We now have an explanation for all's distribution that does not suffer from the circularity of Dowty's distributive subentailments idea. We predict that predicates that do not allow pragmatic weakening should not allow all, and we have independent tests for pragmatic weakening.

Of course, we would still like an explanation for why these predicates do not allow pragmatic weakening. Probably something like Dowty's notion of distributive subentailments will ultimately prove to be relevant. But in the absence of independent evidence for these, the idea doesn't do very much work for us.

Finally, these predicates show an interesting interaction with context, as pointed out to me by Veneeta Dayal (p.c.). In some contexts, these predicates do allow pragmatic weakening, and in these same contexts, we find that all is permitted as well, as expected on the account argued for here.

For example, suppose we are in an elementary school and the students from each grade are electing a president. In this situation, where the students refers to the entire student body, but we understand that it is subgroups of students (by grade) who are doing the electing, it is possible to say (51).

(51) The students have elected a president, but the fourth graders haven't yet.

Where (51) means, the first graders, the second graders, the third graders, and the fifth graders have each elected a president, but not the fourth graders. 
As expected, in this same context, we can say (52).

(52) The students have all elected a president.

Where (52) means every grade has completed its elections.

I take these sentences to be further evidence that we need an account of plurality and all that has a context-dependent component.

\section{2. all and any: A Comparison to Kadmon and Landman (1993)}

The analysis of all proposed here bears a striking resemblance at certain points to the proposal made by Kadmon and Landman (1993) for any. In that paper, Kadmon and Landman give an analysis of any in which several of its properties, including its distribution and its use as a negative polarity item and a free-choice item, follow from its interpretation. Their analysis has three points that are relevant here.

Quantificational Force. Kadmon and Landman propose that any doesn't have quantificational force of its own. Instead an NP with any is an indefinite NP. The apparent quantificational force of any comes from two sources that have been independently shown to be associated with indefinites: the existential force of negative polarity any comes from existential closure, and the universal force of freechoice any comes from generic quantification.

Reduced Tolerance of Exceptions. The contribution of any to a sentence is to indicate "reduced tolerance of exceptions" (p. 356). It does this by performing the operation of 'widening' on the domain of quantification. The idea is that any indicates we should consider a wider domain of quantification, and in so doing will make the statement with any stronger than the corresponding statement without any.

Distribution. The distribution of any follows from its function. If widening the domain doesn't result in a stronger statement, then any is infelicitous. This is the case in, for example, *John saw any woman. Any woman gets existential force in this sentence, and widening the domain of an existential quantifier (not under the scope of negation) does not make the sentence stronger. In contrast, John didn't see any woman is felicitous because if the existential is under the scope of negation, then widening its domain does in fact result in a stronger statement.

Each of these points of Kadmon and Landman's analysis has a counterpart in the proposal I've made here for all. First, I've proposed that all doesn't have any quantificational force of its own, but instead is related to the quantification introduced by the Part operator of a plural predicate.

Second, the maximizing effect is quite similar to the notion of reduced tolerance of exceptions, and the mechanisms employed to account for these notions are similar as well. Maximizing is accomplished by the good fit requirement imposed by all. The effect of requiring a good fit is that the domain of quantification of the Part operator is as wide as it can be with respect to the subject NP.

Finally, the distribution of all is claimed to follow from the fact that if pragmatic weakening is not possible, then all will fail to contribute anything to the sentence, and so be infelicitous. It is only when all has the potential to make the 
sentence a stronger statement that it is felicitous.

\section{3. all and both}

Modulo different cardinality requirements (both presupposes a cardinality of exactly two; all a cardinality of (perhaps) 3 or more) all and both have the same distribution. ${ }^{4}$

Both can occur with strictly distributive predicates as in (53)-(54); it does not disambiguate mixed-extension predicates as in (55)-(56); and it is felicitous with collective predicates as in (57)-(58).

(53) The boys are hungry

(54) The boys are both hungry

(55) The girls built a raft

(56) The girls both built a raft (cf. Every/Each girl built a raft)

(57) The students shared a pizza

(58) The students both shared a pizza

(cf. *Every/Each student shared a pizza (on internally reciprocal reading))

In light of these facts I propose that both, like all, has as its interpretation that it imposes a good fit requirement on the value assigned to Cov. The following translation rule is adapted from (39).

(59) Translation rule for sentences with both:

A sentence of the form [ ${ }_{s} \mathrm{NP}$ both VP] where $\mathrm{N}$ is the translation of NP and $\operatorname{Part}(\mathrm{Cov})(\mathbf{V})$ is the translation of VP, has the following translation: $(\operatorname{Part}(\mathrm{Cov})(\mathrm{V}))(\mathbf{N}) \& \operatorname{gf}(\mathrm{Cov})(\mathbf{N})$

\section{Other Consequences}

\subsection{Questions with Universal Quantifiers}

In this section we will see, first, that the idea that all is not a universal quantifier has some good consequences in addition to those I have already discussed; the case in point is questions with universal quantifiers. Second, I want to show that in at least some cases where all falls in with the class of universal quantifiers we can explain all's behavior without being forced to say that all is itself a universal quantifier, and there we will look at exceptive phrases.

Questions with every in subject position license three different types of answers, as has been shown in the work of Chierchia (1993) and others cited there. These can be called the functional answer (60a), the individual answer (60b) and the pair-list answer (60c). 
(60) Who/which woman did every boy kiss?
a. His mother
b. Judith
c. John kissed Mary, Bill kissed Sue...

If we change every boy to all the boys the list answer is no longer possible.

(61) Who/which woman did all the boys kiss?

a. Their mothers

b. Judith

c. \#John kissed Mary, Bill kissed Sue...

We will see shortly that the possibility of the list answer to (60) hinges crucially on the presence of universal quantifier every in the question. If all is also a universal quantifier, then the oddness of (61c) is quite unexpected. However, in the proposal I have made here we don't expect (61c) to have the same status as (60c).

Before we go on to see how the list answer to (60c) is licensed, I should point out that list answers can also be licensed when both the subject and the object are plural terms. List answers to these questions have been argued by Dayal (1992) and Krifka (1992) to be an independent phenomenon from the list answer shown in (60c). These list answers are related to the phenomenon of dependent plurals (Scha 1981), and do not show subject-object asymmetries. Since all combines with plurals, to avoid interference from this phenomenon I will stick to examples using the unambiguously singular which woman as the object rather than the unmarked-fornumber who.

Chierchia (1993) proposed that the availability of list answers to questions with universal quantifiers is based in part on the fact that a universal quantifier has a minimal witness set that is the set denoted by the common noun.

Let's see in outline how this works. Consider the question (62).

Which woman did every boy kiss?

The structure that Chierchia interprets is shown in (63), and its interpretation is given below in (64).

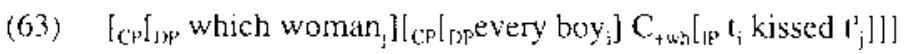

(64) $\lambda \mathrm{P} \exists \mathrm{A}\left[\mathrm{W}\left(\right.\right.$ every.boy',A) $\left.\& \mathrm{P}\left(\lambda \mathrm{p} \exists \mathrm{f} \in\left[\mathrm{A} \rightarrow \mathrm{woman}^{\prime}\right] \exists \mathrm{x} \in \mathrm{A}[\mathrm{p}=\mathrm{kiss}(\mathrm{x})(\mathrm{f}(\mathrm{x}))]\right)\right]$

For Chierchia, the complementizer introduces existential quantification over a function from kissers to kissees. The wh-phrase which woman denotes the set of contextually salient women, and so provides the range of the function. To get the domain of the function, we must be able to extract a set from the denotation of $\mathrm{DP}_{\mathrm{j}}$. If $\mathrm{DP}_{\mathrm{j}}$ is a universal quantifier we can use its minimal witness set, the set of boys, as the domain of the function. 
If all were a universal quantifier then we should expect that this same process would license a list answer to (61). On the other hand, on the analysis I have proposed here we do not expect all to behave like every in this respect, since it is not a universal quantifier. So we do not expect it to license a pair-list reading.

It is quite a straightforward matter to give a derivation for the correct reading. Assume that prenominal all, like floated all, requires a good fit relation between the cover assigned to Cov and the subject NP. Then (65) is interpreted as in (66).

(65) Which woman did all the boys kiss?

(66) $\lambda \mathrm{p} \exists \mathrm{x}\left[\right.$ woman'( $\left.^{\prime}\right) \& \mathrm{p}=\left(\operatorname{Part}(\mathrm{Cov})\left(\operatorname{kiss}^{\prime}(\mathrm{x})\right)\right)($ the.boys') \& $\mathrm{gf}(\mathrm{Cov})($ the .boys')

Another way to say this is that (66) is a set of propositions that looks like (67).

$$
\begin{aligned}
& \{(\text { Part }(\mathrm{Cov})(\text { kiss }(\text { Mary }))(\text { the.boys') \& gf(Cov)(the.boys') } \\
& (\text { Part }(\mathrm{Cov})(\text { kiss }(\text { Sue }))(\text { the.boys') \& } \mathrm{gf}(\mathrm{Cov})(\text { the.boys') } \\
& (\text { Part }(\mathrm{Cov})(\text { kiss }(\text { Ellen }))(\text { the.boys') \& } \mathrm{gf}(\mathrm{Cov})(\text { the.boys' }) \ldots\}
\end{aligned}
$$

So we correctly expect that (65) licenses only the individual answer.

\subsection{Exception Phrases}

In this section I will take one example of a phenomenon where all NP has been shown to behave like universally quantified NP's, and show that we can maintain the generalization, and the analysis of it, without giving up the idea that all NP is not a universal quantifier. We will also see additional evidence for pragmatic weakening. Space restrictions mean I can only give a sketch of the idea.

Von Fintel (1994) shows that there are two types of exception phrases that can be distinguished by their distribution. The distribution of but-phrases is more limited than the distribution of except-phrases, and von Fintel offers an analysis in which the more limited distribution of but-phrases can be explained by their semantics. The data that show the distribution is in (68).
Everyone but Mary
* Most of my friends but Chris
No one but Mary
All my friends but Chris * Some of my friends but Chris *The girls but Chris

The generalization is that only the universal quantifiers allow but-phrases. Von Fintel's explanation for this generalization is that but-phrases require that the exception set they name be the unique exception set that can make the sentence true, and only the universal quantifiers guarantee the uniqueness of an exception set.

The problem we want to address here is how all could behave like a universal quantifier despite the claim I've made that it is not one. To understand this, we first need to see why but-phrases are not permitted with simple definites: we will see that this is because simple definites do not guarantee the uniqueness of the exception set.

Exception phrases are 'domain subtractors.' So, for example, in the sentence 
every student but Donna played volleyball, the but-phrase gives us instructions to subtract Donna from the set of students, and then combine that set with the universal quantifier every. Furthermore, but adds an additional requirement that $\{d\}$ be the unique set of non-playing students.

But because of pragmatic weakening, definite plurals cannot guarantee the uniqueness of the exception set. Imagine we are in a situation where the students denotes $\{\mathrm{a}, \mathrm{b}, \mathrm{c}, \mathrm{d}\}$. The students are in gym class where they are playing volleyball, but Donna is injured, and Bill forgot his gym shorts. Now let's consider (69).

(69) *The students but Donna played volleyball.

Because we allow ill-fitting covers, this sentence could come out true, even though $\{d\}$ is not the unique exception set that makes it so. Bill also did not play volleyball, but this can be captured by means of an ill-fitting cover, in which Bill occupies a cell with non-students. Of course, the sentence could also be true if we said ...but Donna and Bill. But then there are two exception sets that could, depending on the value assigned to Cov, make the sentence true: $\{d\}$ and $\{d, b\}$, and this violates the uniqueness condition imposed by but.

The possibility of ill-fitting covers is what makes it possible to have nonunique exception sets, despite the fact that the Part operator introduces universal quantification over the set of students. Note that without the notion of pragmatic weakening we would not have an explanation for the inability of definites to take butphrases. And since all rules out pragmatic weakening, it does guarantees that there will be a unique exception set, thus explaining why all $N P$ allows a but phrase. So von Fintel's analysis can be preserved, while at the same time we are not forced to conclude that all is a universal quantifier.

\subsection{Complementary Distribution}

Finally, there is another phenomenon that can be explained by the analysis of definites and all that I have proposed here. The following examples show contexts where the and the... all are in complementary distribution, if we take Adam and Bill to be members of the set denoted by the boys. To my knowledge, these facts have not been noted before.

(70) a. Adam and Bill are bald

b. \#In fact, the boys are bald

b'. In fact, the boys are ALL bald

(71) a. If Adam and Bill are bald,

b. \#then the boys are bald

b'. then the boys are ALL bald

(72) a. Which boys are bald?

b. \#the boys are bald 


\section{b'. The boys are ALL bald.}

There are two questions that come up here. One is, why are the (b) sentences infelicitous in a context where the (a) sentences have been uttered? And secondly, what is the role of focus here?

First let us see why (70b), for example, is infelicitous. Since we have supposed that one cannot be sure about the value assigned to Cov, a sentence like (70b) only guarantees that some boy or other is bald (assuming that vacuous quantification is not allowed). It does not entail anything stronger than that. So it is infelcitous following (70a) because, as we have already seen, information entailed by the context cannot be repeated (reinforced) without redundancy. (Sadock 1978)

The examples in (73)-(74) bring out this point. In the same context we see with plural definites above, a sentence with some is infelicitous, but a sentence with most is felicitous, showing that the entailed force of an assertion like (70b) is only as strong as some, and not most (as pointed out to me by Veneeta Dayal).

(73) Adam and Bill are bald. \#In fact, some of the boys are bald.

(74) Adam and Bill are bald. In fact, most of the boys are bald.

Next, we might wonder why focus on the does nothing to alleviate the infelicity of the (b) examples. After all, if the is a supremum operator, why can't we focus it to indicate maximality? And why is focus on all felicitous in the (b') sentences?

It appears that focus on the is felicitous only when the familiarity or uniqueness of the referent is at stake, which is consistent with the Kamp/Heim approach to definites and indefinites. So (75) is perfectly felicitous.

A: I went to a meeting and spoke to a/some/three/a few executive(s).

B: You mean you spoke to THE executive(s) who is/are planning the merger.

Note that the expressions some/three/a few are felicitous only on their 'weak' or 'nonpartitive' readings (see also Buring 1995 on this point). In contrast, on their strong readings they cannot felicitously contrast with the.

(76) A: There were children all over the playground. MOST/SOME/THREE/A FEW children played horseshoes.

B: \#You mean THE children played horseshoes.

So independent of what we say about all, the focus value of the can only contrast familiarity/uniqueness, not proportion.

The account of all proposed here predicts that its focus value should be a set of alternative 'fits,' of which 'good fit' is just one type. We can imagine other sorts of fits for values of Cov, in which some boy or other (or maybe several of them) is in a cell with non-boys. The reader can verify that this means the set of alternatives to (77) is equivalent to (78). 
(77) The boys are ALL bald

(78) $\{$ bald' $(A)$, bald' $(B)$, bald' $(C)$, bald' $(A+B)$, bald' $(A+C) \ldots$ bald' $(A+B+C)\}$

Now we can see why (77) is felicitous as the b' response in (70-72). The theory I have proposed here predicts that (78) is the focus value of (77), and so we expect that a context in which (78) or some part of it is under discussion (as in (70a), (71a), and (72a)) will be one that allows felicitous use of focus on all.

\section{Endnotes}

*I wish to thank Roger Schwarzschild, Maria Bittner, Yael Sharvit, Yoad Winter, students and faculty at Rutgers University, and the audience at SALT for comments, discussion, and suggestions. Special thanks to Veneeta Dayal for her insights on so many levels. Of course I alone am responsible for what is printed here.

1. To keep things simple, I will concern myself in this paper primarily with 'floated' or postnominal all. I do not take a position on the syntactic phenomenon of floating. I expect that what I say about the interpretation of floated all applies as well to prenominal all, at least in general, although there are some differences between them. 2. Landman $(1989,1996)$ allows for some pragmatic weakening by allowing plural noun phrases to denote either 'sums' or 'groups;' one property of groups is that they do not allow distributivity and hence can heave less-than-universal force. However, in his later work it seems that he takes the position that the boys in (11) is not a group, and so he would not allow for pragmatic weakening in this case.

3. Anna Szabolcsi questioned whether it is possible to get weakening even with a set of just two individuals. It is clearly much harder to get pragmatic weakening with a sentence like (i).

i. My parents are tall

Some measure of the difficulty might be attributable to the fact that be tall is an individual-level predicate. In contrast, (ii) seems to be fine if Mom and Dad went to the bowling alley and Dad is only planning to watch.

ii. My parents went bowling.

In addition, Jason Merchant (iii) and Geoff Nunberg (iv) pointed out to me that ever seems to bring out the weakening effect, as in

iii. Have your parents ever been to Europe?

iv. Have the boys ever hit the girls?

Both questions seem to demand an affirmative answer even if only one individual makes the sentence true.

4. Bill Ladusaw tells me that he and several other speakers disagree with some of these judgments. I have checked them with several speakers, though, and found that many people accept (56) and (58). There could be a dialectical difference, or, as he suggested, a generational difference. 


\section{References}

Buring, D. (1996) "The 59th Street Bridge Accent." Ph.D. Diss., Tubingen. Chierchia, G. (1993) "Questions with Quantifiers." Nat. Lang. Sem.1:123-148. Dayal, V. (1992) "Two types of universal terms in questions" in NELS 22.

Dowty, D. (1987) "Collective Predicates, Distributive Predicates, and All." Proceedings of the 3rd ESCOL.

Engdahl, E. (1986) Constituent Questions. Kluwer, Dordrecht.

von Fintel, K. (1994) "Restrictions on Quantifier Domains." Ph.D. diss., U. Mass.

Heim, I. (1982) "The Semantics of Definite and Indefinite Noun Phrases." Ph.D. Diss., U. Mass.

Horn, L. (1991) "Given as new: When redundant affirmation isn't." Journal of Pragmatics 15: 313-336.

Kamp, H. \& U. Reyle (1993) From Discourse to Logic. Kluwer, Dordrecht.

Kadmon, N. \& F. Landman (1993) "Any." Linguistics and Philosophy 16: 353-422.

Krifka, M. (1992) "Definite NP's aren't quantifiers." Linguistic Inquiry 23: 156-163.

Levinson (1983) Pragmatics. Cambridge, New York.

Landman, F. (1996) "Plurality." In S. Lappin, ed., The Handbook of Contemporary Semantic Theory. Blackwell, Cambridge.

Landman, F. (1989) "Groups, I." Linguistics and Philosophy 12: 559-605.

Lasersohn, P. (1995). Plurality, Conjunction, and Events. Kluwer, Dordrecht.

Lasersohn, P. (1993) "Lexical Distributivity and Implicit Arguments." Proceedings of SALT III..

Lasersohn, P. (1990) A Semantics for Groups and Events. Garland Publishing, NY.

Link, G. (1983) "The Logical Analysis of Plurals and Mass Terms: A Lattice-

Theoretical Approach." in Bauerle et al. eds., Meaning, Use, and Interpretation of Language. DeGruyter, Berlin.

Rooth, M. (1992) "A Theory of Focus Interpretation." Nat. Lang. Sem. 1: 75-116.

Sadock, J. (1978) "On testing for conversational implicature." in P. Cole ed., Synat $x$ and Semantics vol 9: Pragmatics. Academic Press, NY.

Scha, R. (1981) "Distributive, Collective, and Cumulative Quantification." In Gronendijk, Stokhof, and Janssen, eds., Formal Methods in the Study of Language. Mathematisch Centrum, Amsterdam.

Schein, B. (1993) Plurals and Events. MIT Press, Cambridge.

Schwarzschild, R. (1996) Pluralities. Kluwer, Dordrecht.

Schwarzschild, R. (1994) "Plurals, Presuppositions, and the Sources of

Distributivity." Nat. Lang. Sem. 2: 201-248.

Schwarzschild, R. (1992) "Types of Plural Individuals." Language and Philosophy 15: 641-675.

Taub, A. (1989) "Collective Predicates, Aktionsarten, and all" in Bach, Kratzer, Partee, eds., Papers on Quantification, University of Mass. 